\title{
Prospecção Tecnológica de Patentes para Equipamento de Segurança Contra Gases Tóxicos e Inflamáveis
}

\section{Technological Patent Prospecting About Safety Equipment for Toxic and Flammable Gases}

\author{
Dorival Tavares da Camara Júnior ${ }^{1}$ \\ Eric Freitas Santos ${ }^{1}$ \\ Marcio Inomata Campos ${ }^{1}$ \\ Gabriela Silva Cerqueira ${ }^{1}$ \\ ${ }^{1}$ Universidade Federal do Oeste da Bahia, Barreiras, BA, Brasil
}

\begin{abstract}
Resumo
Este trabalho pretende verificar o avanço tecnológico na área de segurança contra gases tóxicos e inflamáveis, com interesse na análise de dispositivos totalmente automáticos, programáveis e autônomos, de uso pessoal e industrial. Para a elaboração deste artigo, foram definidas estratégias de pesquisa aplicadas ao banco de dados europeu EspaceNet que resultou em 683 patentes exportadas, sendo estas analisadas por meios de gráficos que representassem aspectos relevantes do mercado. Após a obtenção desses resultados, verificou-se a necessidade de realizar uma análise qualitativa individual de cada patente, que foi feita por meio de resumo e classificada pelo nível de relação com um dispositivo idealizado. Após aplicado esse filtro, o número de documentos reduziu-se para 70 patentes que foram examinadas. Os resultados mostraram que as aplicaçõesforamampliadas com novos produtos, sendo a maioria de nacionalidade chinesa.
\end{abstract}

Palavras-chave: Automatização. Segurança. Gases.

\begin{abstract}
Work carried out in order to verify the technological progress in the area of safety against toxic and flammable gases, with interest in the analysis of fully automatic, programmable and autonomous devices, for personal and industrial use. In order to carry out the work, we defined research strategies applied to the European EspaceNet database, which resulted in 683 exported patents, which were analyzed by means of graphs that represent relevant aspects of the market. After these results, it was verified the need for an individual qualitative analysis of each patent, done by means of the abstract and classified by the level of relation with an idealized device, after applying this filter reduced to 70 patents to be examined. The results showed that the applications were enlarged with new products, being the majority of Chinese nationality.
\end{abstract}

Keywords: Automation. Safety. Gases.

Área Tecnológica: Internet das Coisas. 


\section{Introdução}

A industrialização trouxe praticidade, porém fez com que os centros urbanos se tornassem um risco para as pessoas devido ao alto índice de acidentes, sendo grande parte das ocorrências relacionadas a gases tóxicos ou inflamáveis (gás de cozinha, monóxido de carbono, entre outros) (ALMEIDA, 2017). Pelo fato de a manipulação dessas substâncias ocorrer de maneira manual, há possibilidade de contaminação ou vazamentos, e o diagnóstico depende muito da percepção humana.

No dia 2 de setembro de 2018, foi notificado em todos os veículos de comunicação o incêndio do museu nacional localizado no Rio de Janeiro, ocasionado pela falta de manutenção, resultando na perda de mais de 20 militens do acervo. Nesse caso, observou-se um desfecho que poderia ser minimizado ou até mesmo evitado com a utilização de um simples sistema integrado com sensores de gases, já que, assim, alarmaria logo no início do incidente, ou poderia ainda acionar um outro sistema autônomo de combate a incêndios (REVISTA INCÊNDIO, 2019).

Em 2018, no Brasil, foram contabilizadas 531 ocorrências de incêndio estruturais que poderiam ter sido contornados com a instalação de sprinklers. Entre as diferentes categorias de estruturas, as que registraram o maior número de notícias na imprensa foram os estabelecimentos comerciais (lojas, shopping centers e supermercados), com 190 registros, seguidos por depósitos, com 114 casos. O número de ocorrências de incêndios estruturais noticiados em 2018, classificados por ocupação (exceto residências), apresenta uma maior porcentagem nos incidentes em comércios, indústrias e depósitos, totalizando $73 \%$ dos sinistros (INSTITUTO SPRINKLER, 2019).

Tais problemas fazem surgir uma demanda de aparatos que auxiliam as pessoas no manuseio e no monitoramento de tais compostos, os gases tóxicos e inflamáveis. Com advento da internet e automatização, surgiram possibilidades de acompanhar situações de risco de forma segura e efetiva, acarretando em um considerável aumento da segurança, já que desvincula a percepção humana (WANZELER; FÜLBER; MERLIN, 2019).

Além dos riscos à vida, também há danos significativos provenientes de incêndio, tanto pela perda estrutural quanto pela parada das atividades produtivas da empresa. Desse modo, um investimento direcionado para a segurança estrutural é uma garantia efetiva para que haja perda total do patrimônio (MEDEIROS; FIEDLER, 2004). Em uma visão superficial do mercado de segurança, observou-se um elevado custo para implementação completa (WORTMEYER; FREITAS; CARDOSO, 2005), com central de controle remoto equipada com sensores de gás e um sistema de alerta via Internet das Coisas (IoT). Sendo assim, a presente prospecção tem por objetivo analisar equipamentos de segurança desenvolvidos com intuito de conter, alarmar e detectar substâncias nocivas e/ou inflamável.

A prospecção pode, além de demostrar quais países apresentam maiores índices de depósito de patentes e os principais depositantes (empresas/institutos), identificar as principais pesquisas na área a ser explorada, evitando, assim, o desenvolvimento de protótipos iguais ou semelhantes ou apenas incrementar pontos antes não observados (PEREIRA; CAVALCANTI, 2014). 


\section{Metodologia}

A pesquisa foi realizada junto ao banco de dados europeu EspaceNet, escolhido por apresentar acessibilidade de patentes de diversos países e por ter possibilidade de exportar no formato XLS, facilitando a manipulação em software de planilhas.

Os acessos à base de dados ocorreram no período compreendido entre 22/10/2018 a 22/02/2019, na Universidade Federal do Oeste da Bahia (UFOB) durante o horário de 9h1010 h50 (Horário de Brasília), se estendendo em outros horários e locais quando necessário.

A pesquisa inicial foi feita associando palavras-chave e códigos International Patent Classification (IPC) e Cooperative Patent Classification (CPC). A partir dessas estratégias de pesquisa, foram exportados um total de 683 documentos de patentes, dos quais foram extraídas informações sobre o aspecto e a evolução da área, diferenciando os países, o ano de publicação, os principais depositantes/inventores e os códigos CPC/IPC, que serão descritos a seguir no tópico resultados e discussão.

A Tabela 1 mostra as diferentes configurações utilizadas na base de dados, as linhas marcadas em azul são as estratégias selecionadas para a exportação das patentes.

Tabela 1 - Estratégias de pesquisa

\begin{tabular}{|c|c|c|c|c|c|c|c|c|}
\hline Automat* & Microcontrol* & $\begin{array}{l}\text { toxic } \\
\text { gases }\end{array}$ & LNG & IoT & H04W4/00 & G05B13/00 & CPC & IPC \\
\hline & & & $\mathrm{X}$ & $\mathrm{X}$ & & & & 1 \\
\hline \multirow[t]{3}{*}{$\mathbf{X}$} & & & $\mathrm{X}$ & & & & & 494 \\
\hline & $\mathrm{X}$ & & $\mathrm{X}$ & & & & & 4 \\
\hline & & & $X$ & & X & & 1 & 0 \\
\hline $\mathbf{X}$ & X & & X & & & & & 0 \\
\hline $\mathbf{X}$ & $X$ & & $X$ & X & & & & 0 \\
\hline \multirow[t]{4}{*}{$\mathbf{X}$} & & $X$ & X & & & & 0 & 0 \\
\hline & & & X & & & & 0 & 0 \\
\hline & & $X$ & & $X$ & & & 0 & 0 \\
\hline & $\mathrm{X}$ & $\mathrm{X}$ & & & & & 0 & 0 \\
\hline \multirow[t]{2}{*}{$\mathbf{X}$} & & $\mathrm{X}$ & & & & & & 192 \\
\hline & X & $X$ & X & & & & 0 & 0 \\
\hline \multirow[t]{2}{*}{$\mathbf{X}$} & & $X$ & & & X & & 0 & 0 \\
\hline & $\mathrm{X}$ & $\mathrm{X}$ & $\mathrm{X}$ & & & $X$ & 0 & 0 \\
\hline $\mathbf{X}$ & $X$ & & $X$ & & & & & 0 \\
\hline
\end{tabular}

Fonte: Elaborada pelos autores deste artigo (2019)

A partir das associações de palavras-chave, foi encontrado um maior número de resultados com as seguintes palavras: Automat, LNG e toxic gases. E a combinação com o código G05B13/00 não gerou nenhum resultado.

A Tabela 2 apresenta o significado dos códigos utilizados na pesquisa. 
Tabela 2 - Descrição dos códigos utilizados nesse estudo

\section{Códigos}

H04W4/00

G05B13/00

\section{DESCRIÇÃo}

Serviços especialmente adaptados para as redes de comunicação sem fio.

Sistemas de controle adaptativos, sistemas que se ajustam automaticamente para terem desempenho que seja otimizado em conformidade com algum critério pré-determinado.

Fonte: Elaborada pelos autores deste artigo (2019)

Os códigos de classificação de patentes foram escolhidos de maneira que resultassem patentes relacionadas às tecnologias de sistemas autônomos controlados remotamente, ou seja sistemas pré-programados e de comunicação sem fio.

Após uma análise quantitativa de todas as patentes exportadas, foram gerados alguns gráficos e verificou-se a necessidade de uma análise qualitativa para refinar a pesquisa, tendo em vista que apenas as estratégias aplicadas não foram suficientes para crivar as patentes de real interesse.

A partir dessa análise, optou-se por utilizar o termo ESGTI - que significa Equipamento de Segurança Contra Gases Tóxicos e Inflamáveis - para referir ao protótipo idealizado para uso industrial, domiciliar, comercial e em meios de transporte, com as seguintes características: dispositivo para segurança capaz de detectar gases por meio de sensores para acionar atuadores de emergência que podem cessar focos de incêndio e vazamentos e exaurir gases tóxicos e fumaça, tudo isso atrelado a uma rede informativa que alerta os usuários do dispositivo.

Criou-se uma classificação dos documentos que fazia uma relação entre o ESCGTI e os resumos das patentes, gerando os resultados mostrados na Tabela 3.

Tabela 3 - Classificação relacional com ESCGTI

\section{Relação entre o dispositivo da Patente e o ESCGTI}

$\begin{array}{cc}\text { Semelhante } & 10 \\ \text { Diferente } & 613 \\ \text { Mesma finalidade } & 3 \\ \text { Finalidade parecida } & 12 \\ \text { Mesma Arquitetura } & 1 \\ \text { Arquitetura parecida } & 28 \\ \text { a parecida e Finalidade parecida } & 16\end{array}$

Fonte: Elaborada pelos autores deste artigo (2019)

As patentes classificadas como diferentes foram retiradas, com o intuito afunilar a análise do dispositivo de interesse. Portanto, o número de patentes analisadas reduziu de 683 para 70.

Foram associadas cores a cada classificação, que aparecem nos gráficos e tabelas daqui por diante, pois tais cores compõem o presente artigo com análises que diferenciam as patentes conforme essa classificação. 
Figura 1 - Relação entre o dispositivo da Patente e o ESCGTI

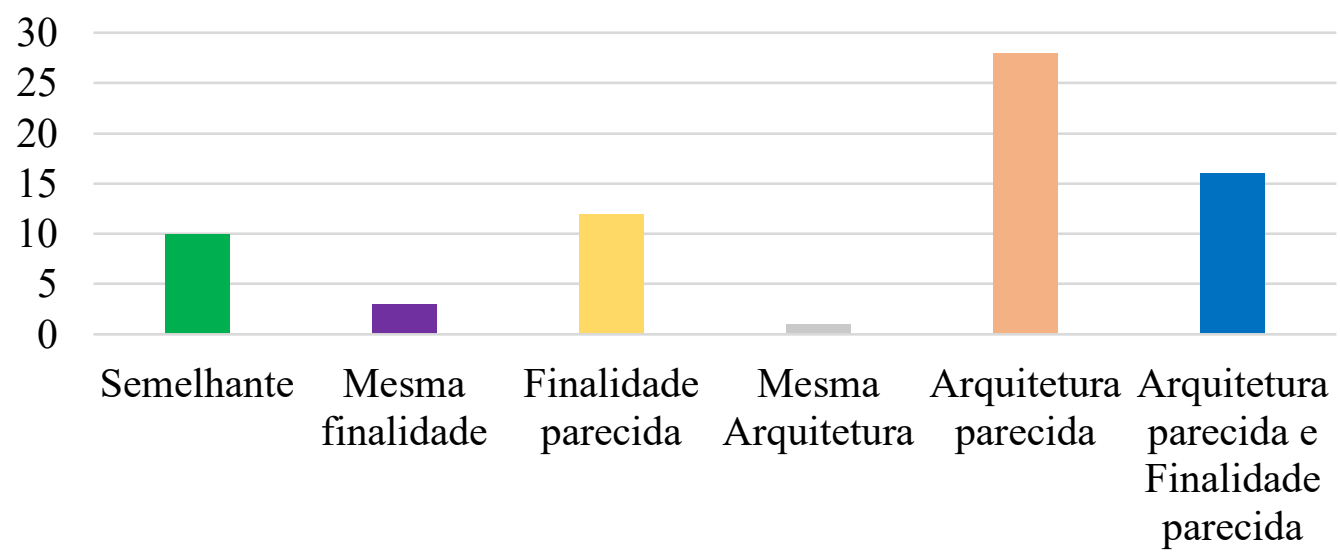

Fonte: Elaborada pelos autores deste artigo (2019)

\subsection{Descrição das Classes Utilizadas}

A seguir, serão elencadas as classes utilizadas:

a) Semelhante: o dispositivo apresenta fortes semelhanças: estruturais, funcionais e na sua finalidade em relação ao ESCGTI.

b) Diferente: o dispositivo não apresenta nenhuma semelhança em relação ao ESCGTI.

c) Mesma finalidade: o dispositivo apresenta arquitetura diferente, porém soluciona a mesma problemática proposta pelo ESCGTI.

d) Mesma Arquitetura: o dispositivo apresenta mesma arquitetura, contudo é aplicado a problemáticas diferentes das do ESCGTI.

e) Finalidade parecida: o dispositivo apresenta arquitetura diferente, contudo soluciona problemáticas parecidas com a proposta do ESCGTI.

f) Arquitetura parecida: o dispositivo apresenta algumas características parecidas com o ESCGTI, porém não é aplicado à mesma problemática.

g) Arquitetura parecida e finalidade parecida: o dispositivo apresenta algumas características parecidas com o ESCGTI e soluciona problemáticas parecidas com a proposta do ESCGTI.

Além da classificação mencionada, foram descritos os tipos de gases detectados e o mecanismo de sensoriamento empregado, sendo essa uma informação específica do dispositivo e apresentada nos resultados com o intuito de referenciar as patentes de acordo com a substância trabalhada para facilitar pesquisas futuras e apontar quais tecnologias estão sendo empregadas nessa área. 


\section{Resultados e Discussão}

Primeiramente foi feita uma análise quantitativa do total de patentes obtidas com as estratégias de busca escolhidas. Como resultado, foram gerados alguns gráficos que foram escolhidos para representar as características julgadas mais relevantes para este trabalho de prospecção.

A Figura 2 apresenta a evolução do número de patentes depositadas a cada ano; no período de 1905 a 1980, constatou-se um número muito baixo de depósitos, por isso, a fim de melhorar a viabilidade da análise, foi feito um segundo gráfico como zoom do período de 1981 a 2018.

Figura 2 - Evolução anual

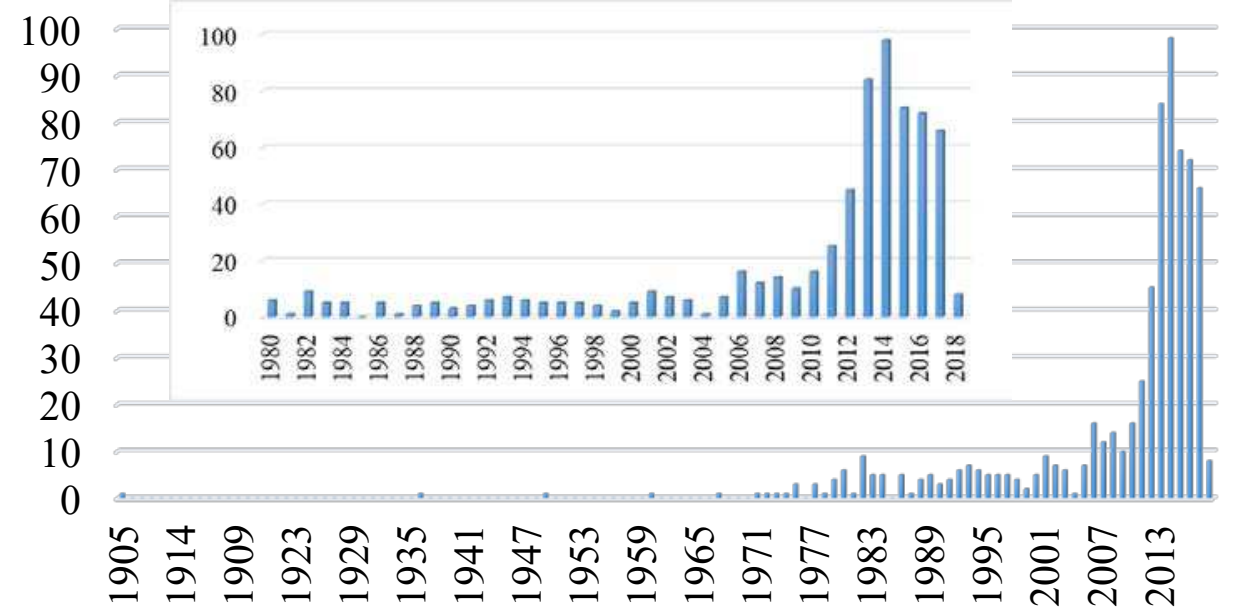

Fonte: Elaborada pelos autores deste artigo (2019)

No intervalo de 1905 a 1973, houve poucos depósitos de patentes (abaixo de uma patente por ano), e o conteúdo das patentes desse período eram diferentes do foco da prospecção. Com o passar dos anos, no período de 1973 a 2001, houve desempenho oscilante, porém melhor do que o do intervalo anterior. É possível justificar essa variação pelo fato de ocorrer desenvolvimento de materiais e semicondutores, tornando os equipamentos mais acessíveis devido à intensificação do ramo tecnológico fomentado pelos países asiáticos - o que possibilitou a utilização de novas tecnologias em produtos para o mercado comum.

Nos anos de 2001 a 2005, aconteceu uma redução de $22 \%$ do número de depósitos de patentes em relação aos anos de 1995 a 2000. Nos anos sucessores, de 2006 a 2013, ocorreu um aumento gradativo (média de 200\%), quase atingido a marca de 100 depósitos no último ano. Pode-se relacionar o aumento nos últimos anos à popularização de termos como IoT $e$ automatização, em conjunto com o comércio de microcontroladores de baixo custo.

Nos anos sucessivos, verifica-se uma diminuição no número de patentes, sendo que, a partir do ano de 2017, essa queda é justificada pelo período de sigilo, no qual as patentes não são publicadas na base de dados por 18 meses contados a partir da data do depósito.

A Figura 3 classifica os países pelo número de patentes em ordem crescente, apresentando ainda os depósitos da Organização Europeia. 
Figura 3 - Principais países depositantes

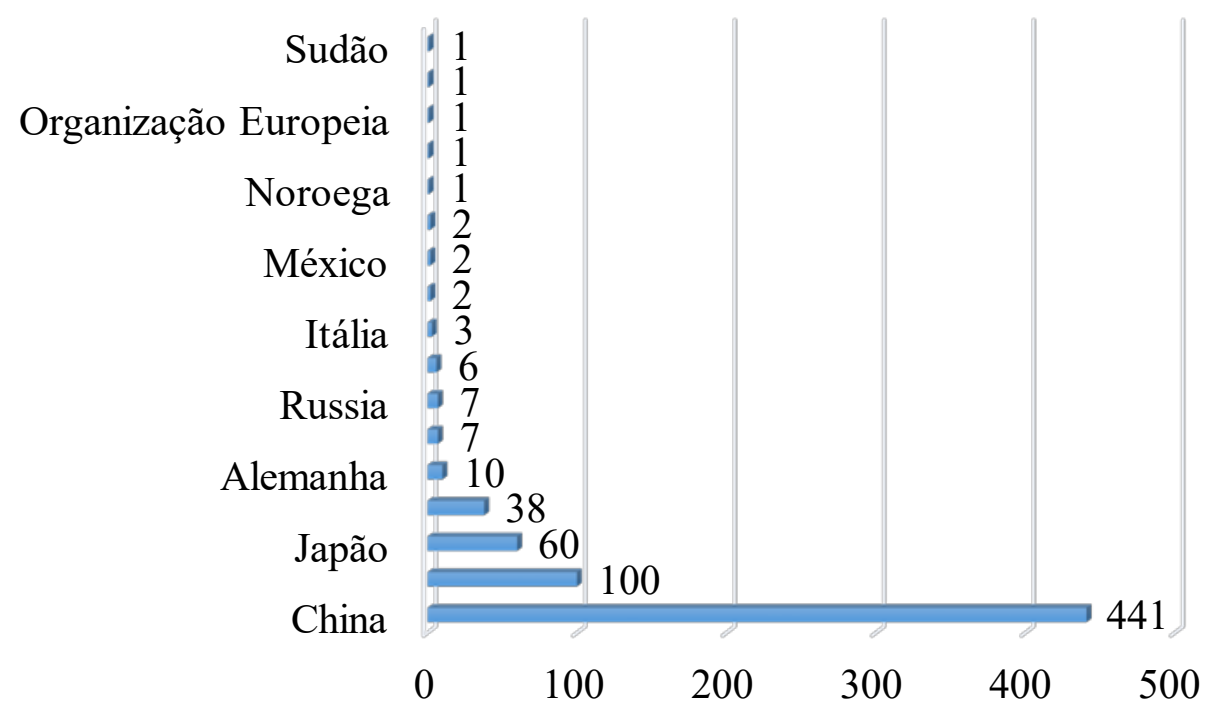

Fonte: Elaborada pelos autores deste artigo (2019)

Como mencinado anteriormente, os países asiáticos estão se destacando durante o século XXI como potências econômicas devido ao comércio e ao desenvolvimento de novas tecnologias. Sendo assim, a China aparece como principal país depositante a partir do ano 2000, e esse número é superior, se comparado ao resto do mundo; em segunda posição está a Coreia do Sul, também uma nova potência tecnológica e, em seguida, estão os outros países já consagrados no ramo de tecnologias, como Japão, EUA e Alemanha.

A Figura 4 mostra os nove inventores com mais patentes associadas a seus nomes, com siglas indicando também a sua nacionalidade, sendo $\mathrm{CN}$ relativo à China e $\mathrm{KR}$, à República da Coreia (Coreia do Sul).

Figura 4 - Inventores mais frequentes

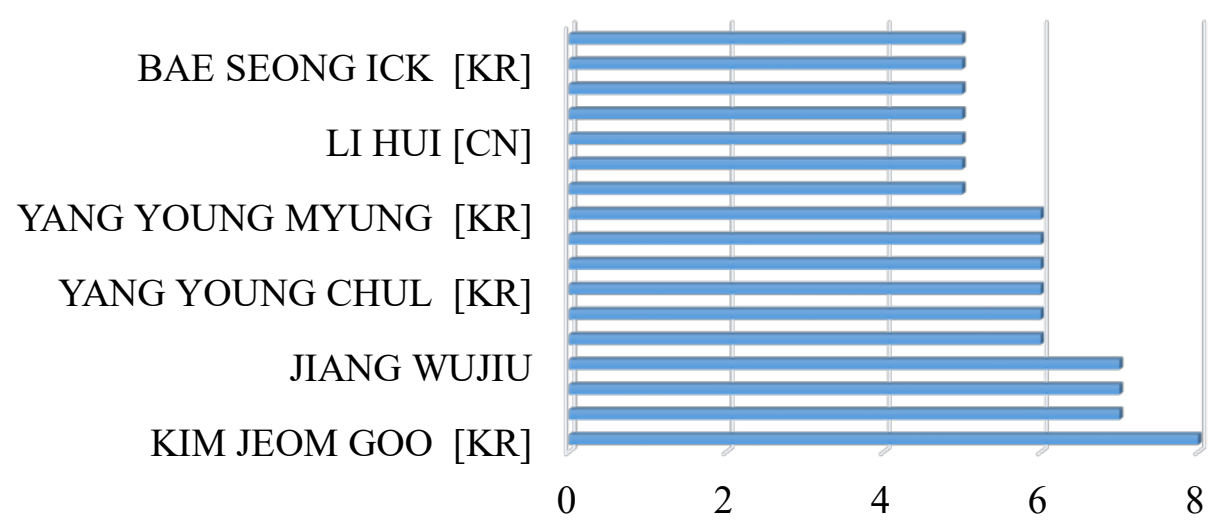

Fonte: Elaborada pelos autores deste artigo (2019)

Observa-se o domínio dos países asiáticos na liderança na área desta pesquisa, sendo a Coreia do Sul líder quantitativo de pesquisadores (Figura 5), com cinco dos nove pesquisadores, além disso, o país possui a maior soma numérica de depósitos. Em seguida, vem a China, mantendo também um expressivo número de pesquisadores e de dispêndio.

A Figura 5 mostra os 14 depositantes com mais patentes associadas a seus nomes indicando a sua nacionalidade. 
Figura 5 - Depositantes mais frequentes

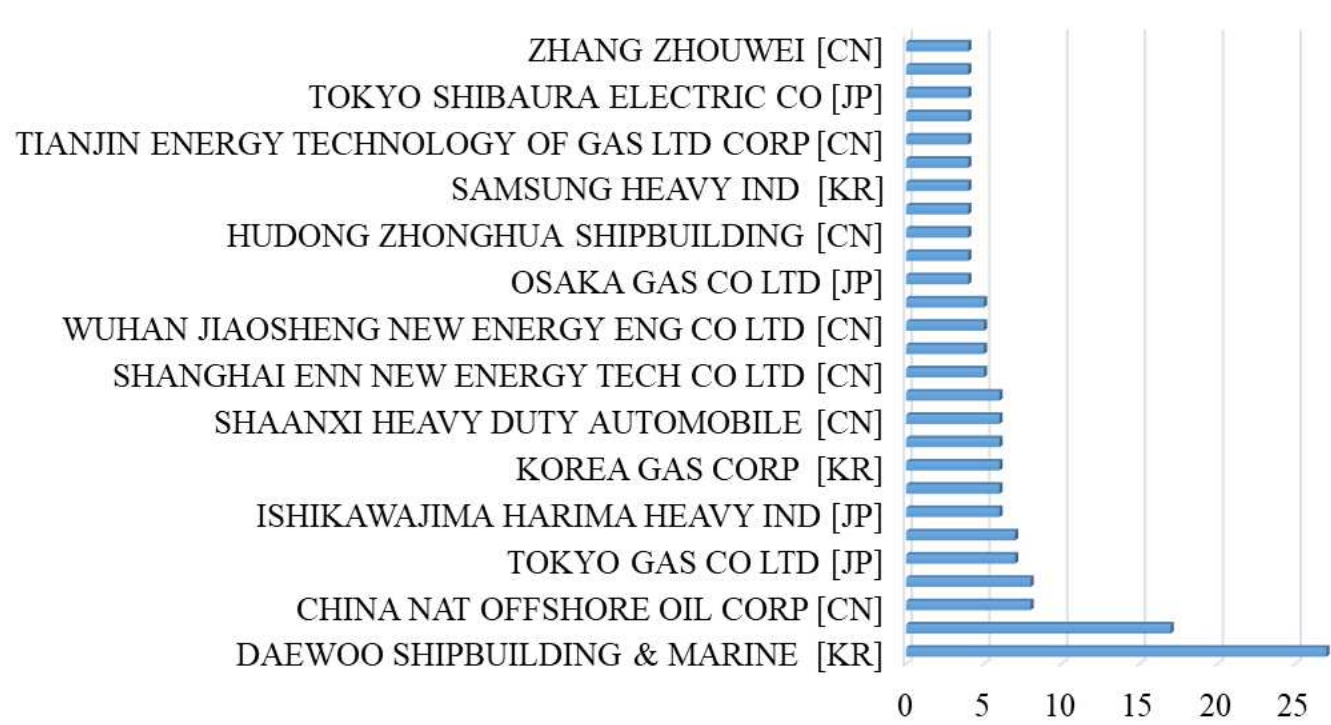

Fonte: Elaborada pelos autores deste artigo (2019)

Das depositantes mais frequentes, quatro são japonesas, três coreanas e sete chinesas. A Coreia do Sul se mantém líder consolidada com a empresa Daewoo Shipbuilding e Marine no ramo de engenharia naval; seguida pela empresa governamental chinesa China Nat Offshore Oil Corp com matrizes energéticas (óleo e gás natural, GNL). Em seguida, é possível observar duas empresas japonesas, a Tokyo Gas Co Ltd., atuante nos seguimentos energéticos (GNL), e a empresa IHI Corporation, atuante na engenharia naval.

Em relação às Figuras 6 e 7, foram combinados os códigos com termos específicos da área, por isso, foi possível captar patentes com mecânicas similares, divergindo-se apenas nas suas finalidades. Isso possibilitou absorver outros códigos (IPC/CPC) comuns às patentes e aferir o número de documentos similares.

Figura 6 - Códigos IPCs mais frequentes

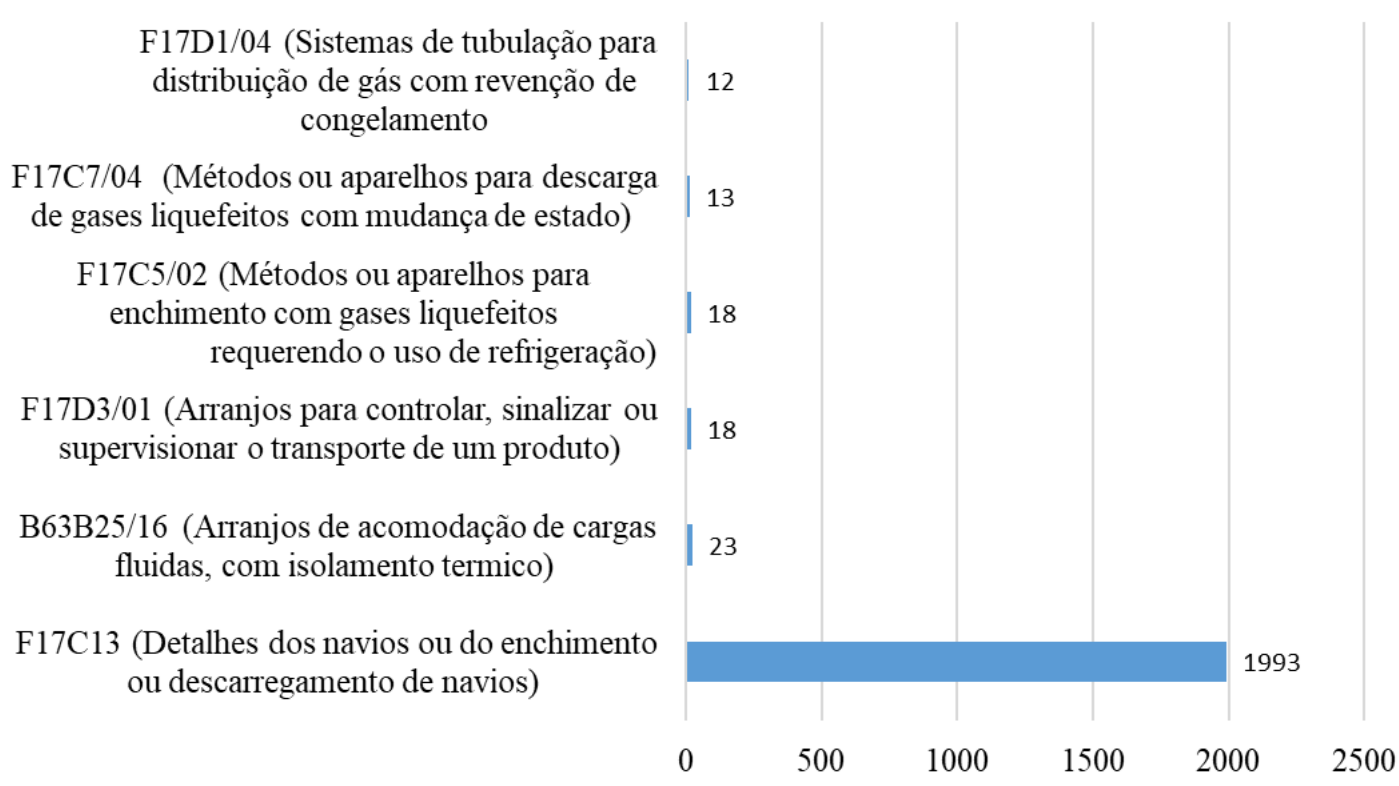

Fonte: Elaborada pelos autores deste artigo (2019) 
O código F17 apresentou várias subseções. Para entender melhor os dados da Figura 6, foram contraídas apenas para a seção F17C13 que disparadamente teve 1.993 patentes, percebendo-se, assim, que a maioria dos registros estão relacionados com o enchimento e o descarregamento de navios, isso se deve ao fato de o principal meio de transporte de óleos, gases e derivados do petróleo serem feitos por vias navais.

Figura 7 - Códigos CPCs mais frequentes

F17C7/04 (Descarregamento de gases liquefeitos com mudança de estado, por exemplo, vaporização)

B23K2101/12 (Artigos feitos por solda, soldagem ou corte, tubulares ou ocos, para embarcações)

F17C2223/033 (Fluido armazenado a baixa pressão)

Y02T 10/32 (Veículos de transporte rodoviario que utilizam combustiveis gasosos)

F17C2223/0161 (Fluido bifasico como gás liquefeito amarzenado em temperatura criogênica)

F17C2221/033 (Fluido manipulado do tipo metano)

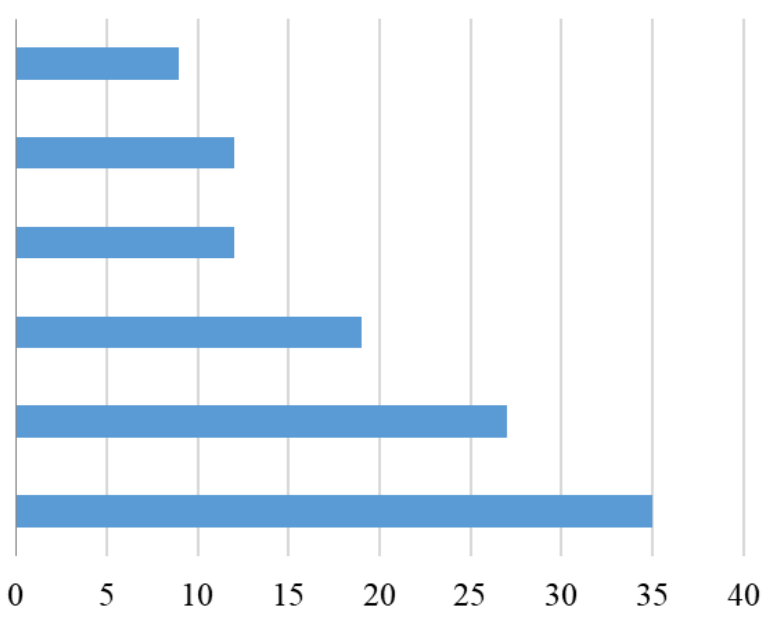

Fonte: Elaborada pelos autores deste artigo (2019)

Nos códigos CPCs nota-se uma maior variação dos principais códigos, sendo o mais frequentes o F17C2221/033, relacionado à manipulação do metano, caracterizando um bom resultado das estratégias de pesquisa, tendo em vista que foi utilizada a palavra-chave "LNG" sigla inglesa para gás natural liquefeito, que tem como componente principal o metano.

A partir desse ponto foram apresentados os dados referentes à segunda estratégia de seleção, baseada na análise e na classificação dos resumos. Cada gráfico, além de apresentar a variável principal (exemplo: classificação por países, a variável é país), também divide essa variável de acordo com a classificação dada com base na leitura do resumo, sendo representada sempre pelas mesmas cores de classificação que foram explicitadas na metodologia.

A Figura 8 classifica os países pelo número de patentes em ordem crescente, apresentando ainda os depósitos na base da Organização Europeia.

Figura 8 - Principais países

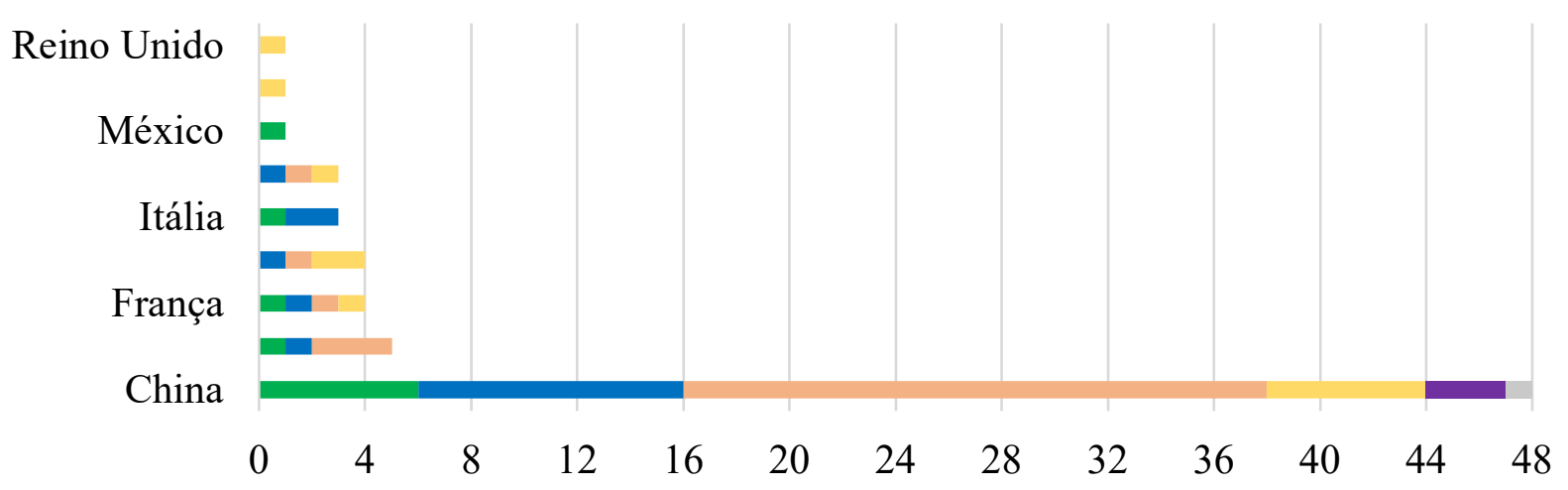

Legenda: - Semelhante $\square$ Mesma finalidade $\quad$ Mesma Arquitetura $\square$ Arquitetura parecida Arquitetura parecida e Finalidade parecida

Fonte: Elaborada pelos autores deste artigo (2019) 
É de fundamental importância observar os países que apresentam materiais na mesma linha de pesquisa, pois eles mantêm como prioridade a solicitação de proteção neles, em "Arquitetura parecida" possibilitando verificar as linhas tecnológicas estudadas. Por exemplo, na China, há grandes frentes de pesquisa na área, logo, percebe-se a necessidade da solicitação de proteção de um possível novo invento.

A Figura 9 apresenta a evolução do número de depósitos de patentes a cada ano, o Gráfico $\mathrm{B}$ mostra o número de patentes no ano e a imagem menor, o Gráfico $\mathrm{A}$, apresenta a evolução acumulativa.

Figura 9 - Evolução anual e evolução anual acumulativa

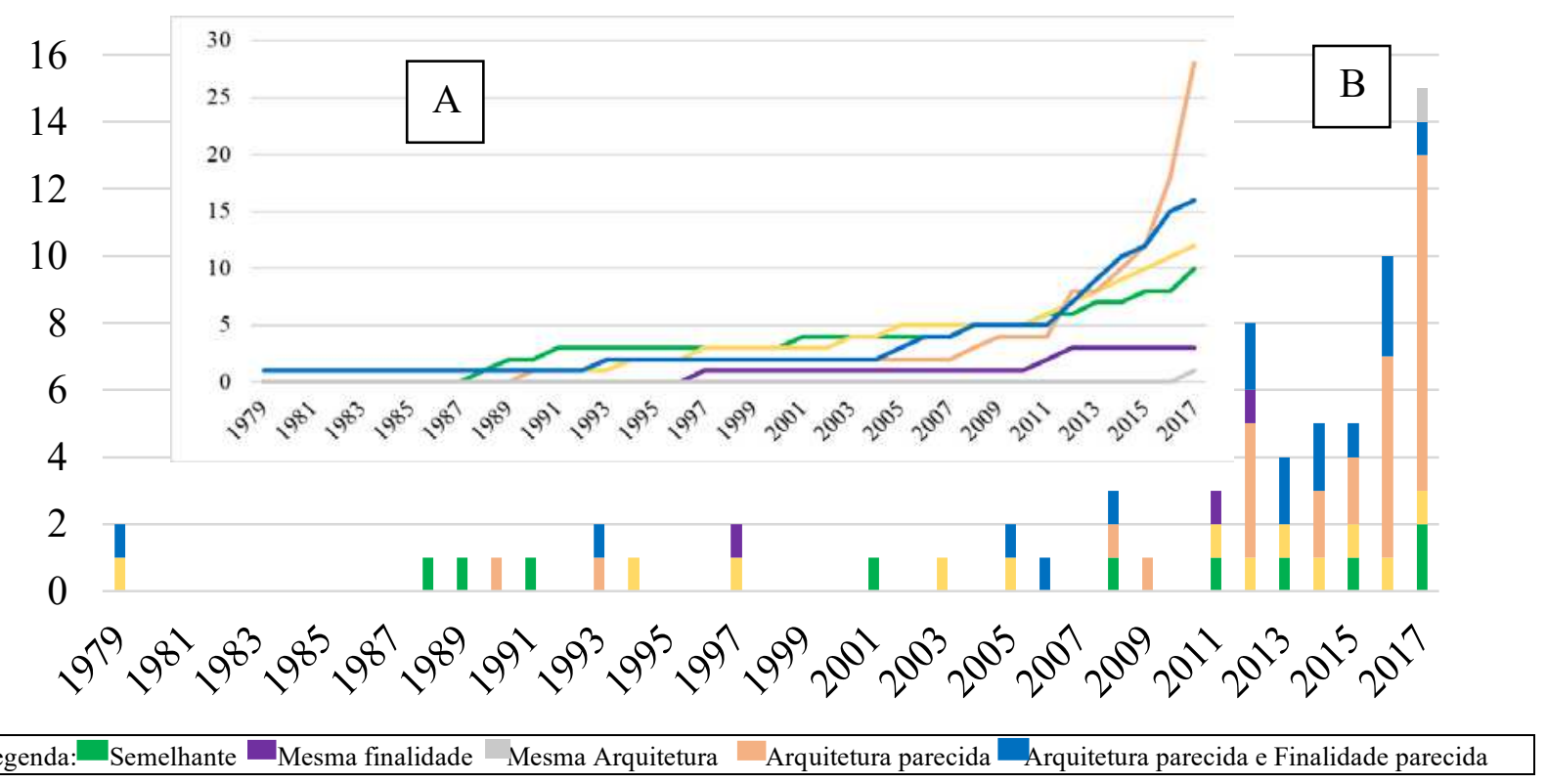

Fonte: Elaborada pelos autores deste artigo (2019)

Durante os primeiros 30 anos (1979-2009) ocorreu o início da utilização de componentes eletrônicos em produtos em escala comercial, mas ainda com custo muito elevado, o nicho de mercado era restrito e, assim, a finalidade era bem definida (Figura 9). A partir do ano de 2008, observa-se uma elevação nos parâmetros que correspondem à expansão da aplicação de sensores em outras problemáticas. Nos anos posteriores, nota-se o aumento gradual na classificação "Mesma finalidade", condizente com a ampliação da utilização de microcontroladores em outros setores.

As Figuras 10 e 11 apresentam os códigos CPCs e IPCs relacionados às patentes que tinham algum grau de semelhança com o ESCGTI. 
Figura 10 - Códigos CPCs mais frequentes

F17C2223/0161 (Gás liquefeito armazanado antes da transferencia a temperatura criogênica)

F17C2225/0123 (Fluido manipulado após a transferência de fase única, gasoso)

F17D3/01 (Arranjos para controlar, sinalizar ou supervisionar o transporte de um produto)

F17C7/04 (Métodos ou aparelhos para descarga de gases liquefeitos com mudança de estado)

F17C2221/033 (Fluido manipulado do tipo metano)

F17C13(Detalhes dos navios ou do enchimento ou descarregamento de navios)

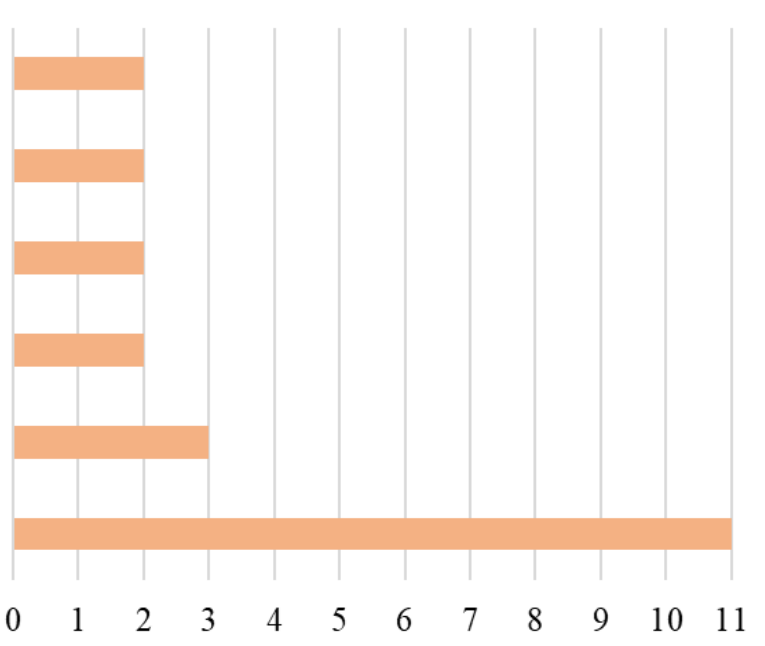

Fonte: Elaborada pelos autores deste artigo (2019)

Os códigos mais frequentes de classificação CPC se encontraram apenas em patentes que foram classificadas como "Arquitetura parecida". São todos subseções da seção F17: dispositivos para armazenagem de gases ou líquidos de distribuição, mostrando maior linha de pesquisa voltada para o ramo do comércio em grande escala de gás natural, combustíveis gasosos e líquidos e derivados do petróleo.

Figura 11 - Códigos IPCs mais frequentes

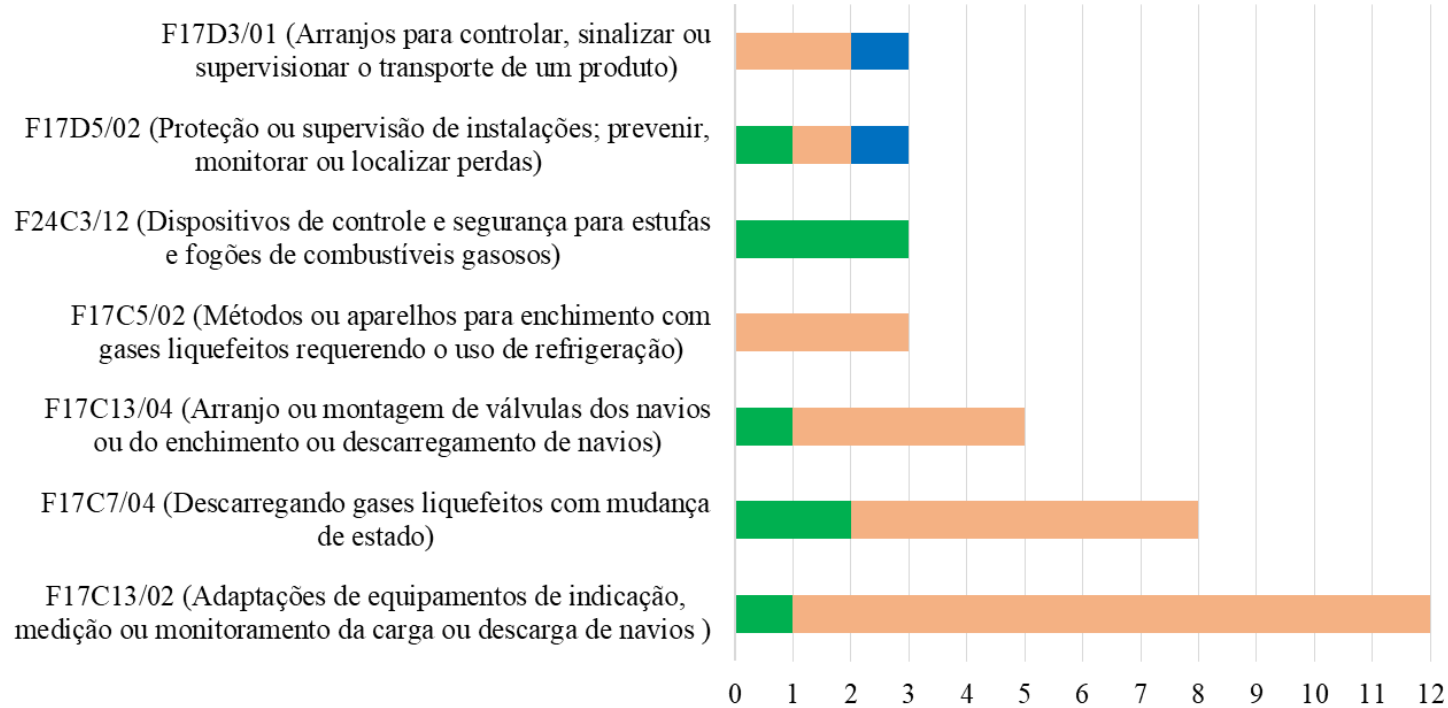

Legenda: $\quad$ Semelhante $\square$ Mesma finalidade $\quad$ Mesma Arquitetura $\quad$ Arquitetura parecida Arquitetura parecida e Finalidade parecida

Fonte: Elaborada pelos autores deste artigo (2019)

Os códigos IPCs mais frequentes se distribuíram entre três relações com o ESCGTI: Semelhante, Arquitetura parecida e Arquitetura e Finalidade parecidas. Teve maior ênfase a seção F24C3/12, que estava associada a três patentes classificadas como semelhantes. Analisando a descrição da seção F24C3/12, observa-se que se trata realmente de um código ideal para buscas com os fins aqui apresentados, pois expressa um possível mercado consumidor para o ESGTI. 
A Figura 12 mostra os três depositantes mais frequentes.

Figura 12 - Principais depositantes

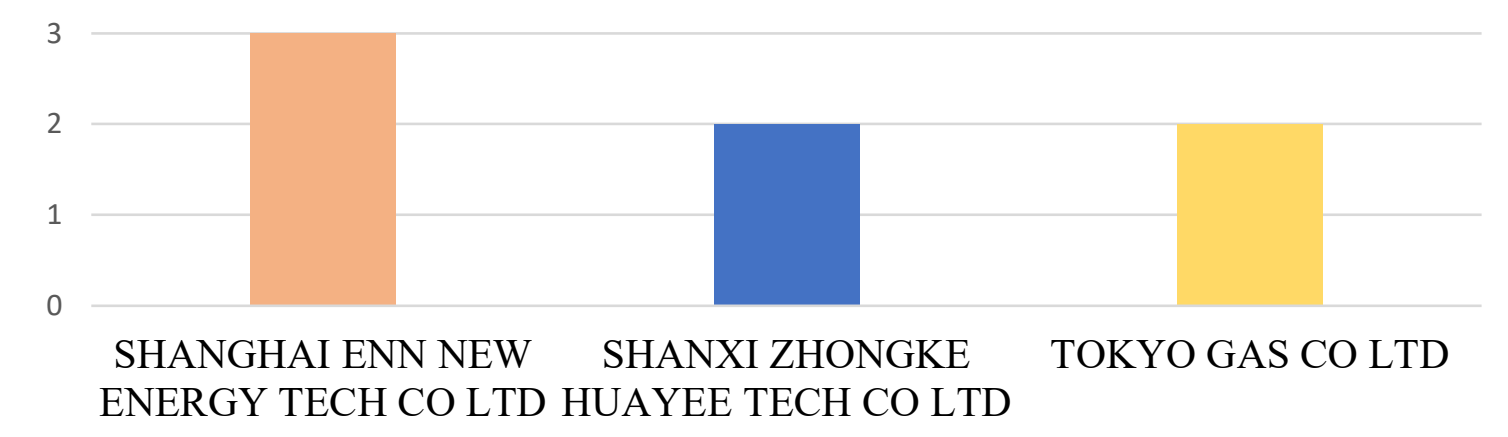

Legenda: - Semelhante $\square$ Mesma finalidade Mesma Arquitetura ${ }_{\text {arquitetura parecida }}$ arquitetura parecida e Finalidade parecida

Fonte: Elaborada pelos autores deste artigo (2019)

O principal depositante registrou todas as patentes com "Arquitetura parecida" com o ESCGTI; os dois segundos registraram dispositivos com "Arquitetura e Finalidade parecidas" $e$ "Finalidade parecida" com o ESCGTI. Constatou-se que não há muitas empresas que insvestem em um produto igual, isso é um sinal de que o mercado não está saturado, pois apesar de estar crescendo a uma taxa muito alta, áreas como a Internet das Coisas ainda estão em processo de consolidação no mercado.

A empresa japonesa Tokyo Gas Co Ltd., atuante nos seguimentos energéticos (GNL), depositou duas patentes, sendo estas um método de inspeção de fuga junto com aparelho de inspeção de vazamento e a outra um método de monitoramento para o braço de descarga de GNL.

A Figura 13 mostra os tipos de substâncias que foram identificadas, no resumo, como objeto de aplicação das patentes.

Figura 13 - Tipos de gases envolvidos

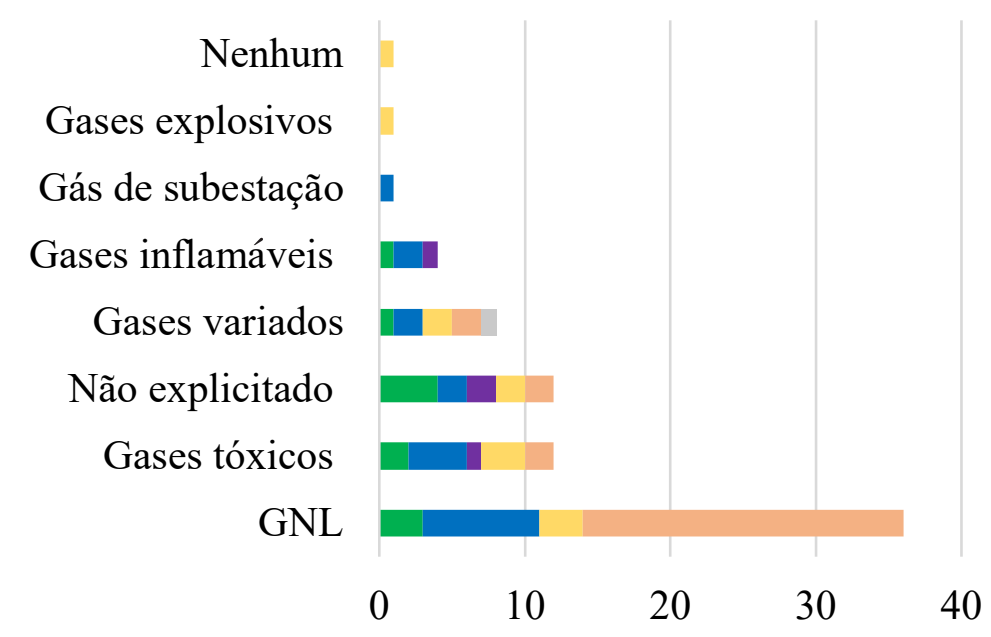

Legenda: $\_$Semelhante $\square$ Mesma finalidade $\quad$ Mesma Arquitetura $\quad$ Arquitetura parecida $\square$ Arquitetura parecida e Finalidade parecida

Fonte: Elaborado pelos autores deste artigo (2019) 
Como era de se esperar, o GNL foi o mais encontrado, já que foi utilizado como palavra-chave nas buscas, mas, além deste, foram encontrados outros gases cujo monitoramento utiliza automação e Internet das Coisas. O GNL foi seguido pelos gases tóxicos que, por apresentarem um grau que periculosidade maior, acabam atraindo pesquisados e acionistas para o desenvovimentos de tecnologias de segurança.

Na Figura 14 constam os tipos de sensores utilizados, tais informações foram retidas a partir do resumo, por isso, em muitas patentes, não foi possível identificar o sensor, pois não explicitavam no resumo.

Figura 14 - Tipos de sensores utilizados

Sensor de capacitância Sensor de hidrogênio e oxigênio Transdutor Sensor de Pressão e temperatura Sensor de dióxido e de monóxido carbono. Sensor de gases tóxicos e inflamáveis Nenhum Semicondutor sensível a gases Não explicitado

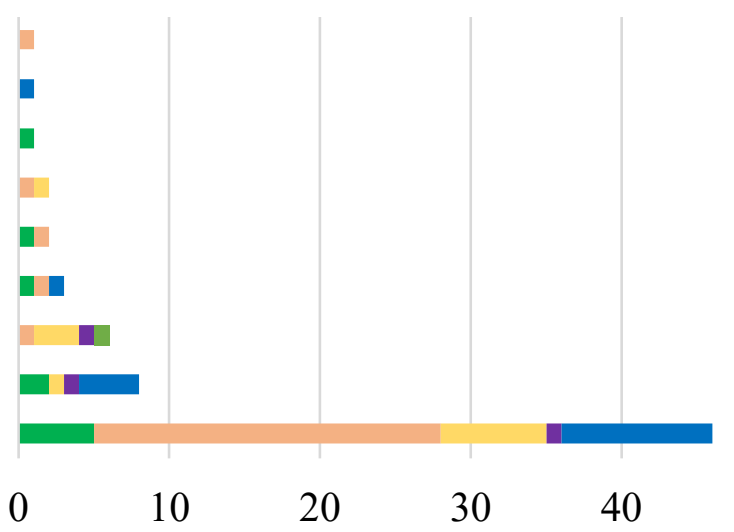

Legenda: $\quad$ Semelhante $\square$ Mesma finalidade - Mesma Arquitetura $\quad$ Arquitetura parecida $\square$ Arquitetura parecida e Finalidade parecida

Fonte: Elaborada pelos autores deste artigo (2019)

O semicondutor sensível a gás é o mais utilizado por ser uma tecnologia bastante difundida e utilizada na eletrônica. Nos demais, há alguns sensores específicos utilizados, a maioria deles é sensor de algum gás, porém é curioso saber que, para o monitoramento de gases, são implementados também outros tipos de sensores, por exemplo, os sensores de pressão e de temperatura, pois, com determinados dispositivos, é possível identificar um vazamento pela variação de pressão ou temperatura em um tanque pressurizado.

A Figura 15 mostra a porcentagem de depósitos associados ao setor privado e ao setor público, mostrando também a porcentagem das invenções registradas por pessoas físicas.

Figura 15 - Principais setores

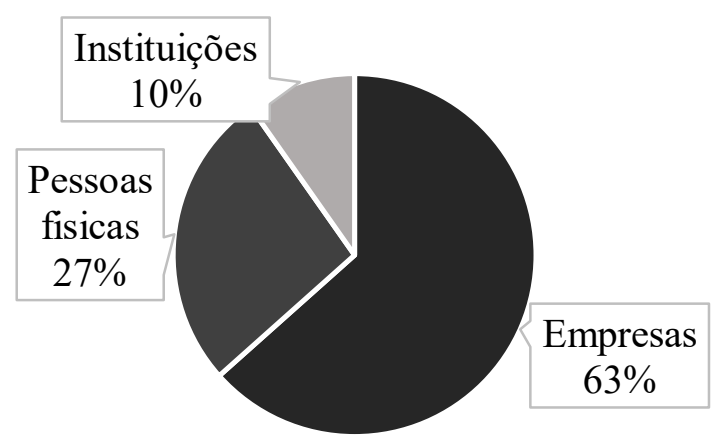

Fonte: Elaborada pelos autores deste artigo (2019) 
Naturalmente, o setor que mais agregou registros foi o das empresas, pois o registro surge como pré-requisito da comercialização, que é o objetivo da empresa quando investe em inovação. Depois das empresas, foram as pessoas físicas, já que algumas pessoas compartilham do mesmo interesse das empresas, porém com um déficit maior de recursos. Observa-se que as instituições renderam o menor número de registros.

\section{Considerações Finais}

A análise inicial dos documentos de patentes recuperados com as estratégias escolhidas, sem a leitura dos resumos, se mostrou relevante para uma visão geral da linha em que as tecnologias de automação por sensoriamento remoto estão sendo empregadas, mas, com a leitura do resumo das patentes, foram constatadas informações específicas, nas quais foram verificadas implementações no ramo da segurança no transporte de gás natural liquefeito por vias marítimas.

Em parte dos pedidos depositados há uma semelhança acentuada na arquitetura com o ESCGTI, divergindo apenas nas implementações e funcionamento, isso se dá pelo crescente uso de tecnologias de automação nas mais diversas áreas, inclusive o surgimento da própria indústria 4.0; em segunda posição surge a associação de arquitetura e finalidade parecidas com o ESCGTI, destaque nesses itens, pois são informações viáveis para incorporar no invento ampliando suas funcionalidades e recursos. As classes "Mesma Finalidade" e "Finalidade parecida" com o ESCGTI possibilitaram a análise de outros sistemas para solucionar a mesma problemática, enquanto a classe "Igual" ao ESCGTI alertou para alterações necessárias do dispositivo, aprimoramentos e setores para implementação.

A tecnologia pesquisada apresenta fortes indícios de fase de maturidade embrionária, indícios que mostram o crescente o número de depósitos e uma gama diversa de depositantes, revelando que há possibilidades de mercado referentes a essa linha de pesquisa.

\section{Referências}

\section{ALMEIDA, L. A. S. Monitoramento dos gases existente em espaço confinado de uma} unidade armazenadora de grãos. 2017. 78f. Monografia (Graduação em Engenharia Elétrica) Universidade Regional do Noroeste do Estado do Rio Grande do Sul, Rio Grande do Sul, 2017.

INSTITUTO SPRINKLER. [2019]. Disponível em: https://www.sprinklerbrasil.org.br/institutosprinkler-brasil/estatisticas/estatisticas-2018/. Acesso em: 8 fev. 2019.

MEDEIROS, M. B.; FIEDLER, N. C. Incêndios florestais no parque nacional da serra da canastra: desafios para a conservação da biodiversidade. Ciência Florestal, Santa Maria, [s.l.], v. 14, n. 2, p. 157-168, 2004.

PEREIRA, L. C.; CAVALCANTI, G. D. C. Metodologia para Avaliar Técnicas de Redução de Protótipos: Protótipos Gerados versus Protótipos Selecionados. In: ENIAC, 2014. São Carlos, SP, de 18 a 23 de outubro de 2014. Anais [...]. São Carlos, SP, 2014.

REVISTA INCÊNDIO. [2019]. Disponível em: http://revistaincendio.com.br/sistema-de-deteccao-ealarme-de-incendios-um-aliado-na-protecao-de-patrimonios-historicos-e-culturais-brasileiros/. Acesso em: 8 fev. 2019. 
WANZELER, T.; FÜLBER, H.; MERLIN, B. Desenvolvimento de um sistema de automação residencial de baixo custo aliado ao conceito de Internet das Coisas (IoT). In: XXXIV SBrT, 2016. Santarém, PA, de 30 de agosto a 2 de setembro de 2016. Anais [...]. Santarém, PA, 2016.

WORTMEYER, C.; FREITAS, F; CARDOSO, L. Automação Residencial: Busca de Tecnologias visando o Conforto, a Economia, a Praticidade e a Segurança do Usuário. In: II SEGET, 2005. Rio de Janeiro, RJ, de 3 a 6 de setembro de 2005. Anais [...]. Rio de Janeiro, RJ, 2005.

\section{Sobre os Autores}

\section{Dorival Tavares da Camara Júnior}

E-mail: juniordorival4000@gmail.com

Bacharel em Ciência e Tecnologia pela UFOB em 2019.

Endereço profissional: Universidade Federal do Oeste da Bahia, Campus Reitor Edgard Santos, Rua Bertioga, $\mathrm{n}$. 892, Morada Nobre I. Barreiras, BA. CEP: 47810-059.

\section{Eric Freitas Santos}

E-mail: ericfreita307@gmail.com

Bacharel em Ciência e Tecnologia pela UFOB em 2019.

Endereço profissional: Universidade Federal do Oeste da Bahia, Campus Reitor Edgard Santos, Rua Bertioga, n. 892, Morada Nobre I. Barreiras, BA. CEP: 47810-059.

\section{Marcio Inomata Campos}

E-mail: marcioinomata@gmail.com Doutor em Engenharia Química pela UFBA em 2016.

Endereço profissional: Universidade Federal do Oeste da Bahia, Campus Reitor Edgard Santos, Rua Bertioga, n. 892, Morada Nobre I. Barreiras, BA. CEP: 47810-059.

\section{Gabriela Silva Cerqueira}

E-mail: gabriela.cerqueira@ufob.edu.br Doutor em Química pela UFBA em 2017.

Endereço profissional: Universidade Federal do Oeste da Bahia, Campus Reitor Edgard Santos, Rua Bertioga, n. 892, Morada Nobre I, Barreiras, BA. CEP: 47810-059. 